\section{Origins of breathable air}

\author{
Heinrich D. Holland
}

THE high oxygen content of the Earth's atmosphere sets our planet apart from all other bodies in the Solar System. It has been clear for some time that aimospheric $\mathrm{O}_{2}$ is almost entirely the product of photosynthesis by green plants, but neither the mechanism that controls its partial pressure today nor how oxygen levels have varied during the Earth's history are well understood. Progress on the latter problem, reported at a recent meeting*, has, if anything, set back progress on the former, insofar as control mechanisms previously thought likely now seem improbable.

It is now generally accepted that $\mathrm{O}_{2}$ was present in the atmosphere in vanishingly small amounts until the development of green-plant photosynthesis (J.F. Kasting, Pennsylvania State University). There is compelling evidence that more than 1,900 million years (Myr) ago, the $\mathrm{O}_{2}$ content of the atmosphere was much lower than today, perhaps as little as 1 per cent of the present level ( 21 per cent). Recent studies of fossil soils indicate that the partial pressure of $\mathrm{O}_{2}\left(p_{0}\right)$ rose at least fifteenfold 1,900 Myr ago. The deposition of the enormous banded iron formations which were so important during the preceding 2 billion years ceased at that time, possibly because the rise in $p_{\mathrm{O}_{2}}$ may well have led to the oxygenation of the deeper parts of the oceans. $\mathrm{Fe}^{2+}$ from hydrothermal vents would then have been oxidized and precipitated rapidly on the ocean floor as oxides or hydroxides of $\mathrm{Fe}^{3+}$, much as they are today. This would have reduced or eliminated the supply of iron to the shallower parts of the oceans where the banded iron formations had been deposited.

The reasons for the rapid rise in atmospheric $\mathrm{O}_{2}$ at that time are not known. The oldest well documented fossils of eukaryotic organisms occur in rocks about 1,700 Myr old. Eukaryotes may have played a role in the rise of $p_{0}$, but they may simply have been beneficiaries of the atmospheric improvements.

The long delay - more than 1,000 million years - between the first rise of atmospheric $\mathrm{O}_{2}$ and the development of the metazoa towards the end of the Proterozoic is still puzzling. During the past few years A.H. Knoll (Harvard University) and J.M. Hayes (University of Indiana) have shown that many limestones deposited between 900 and 600 Myr ago have anomalously high ${ }^{13} \mathrm{C}$ content, which could be due to the burial of extraordinarily large quantities of organic matter. If so, the $\delta^{1:} \mathrm{C}$ values may indicate that $p_{\mathrm{O}_{2}}$ increased very significantly

*Atmospheric Oxygen-Variation through Geological Time Pennsyivania State University, 16-18 July 1990. during this period; but the ${ }^{13} \mathrm{C}$ data can also be interpreted in other ways, and it is not yet certain that the evolution of the metazoa was related to a late Proterozoic increase in atmospheric $\mathrm{O}_{2}$.

The $\mathrm{O}_{2}$ content of the atmosphere during the past $350 \mathrm{Myr}$ is much better constrained than during the Precambrian. Currently, the most interesting limits on atmospheric $\mathrm{O}_{2}$ during the Phanerozoic

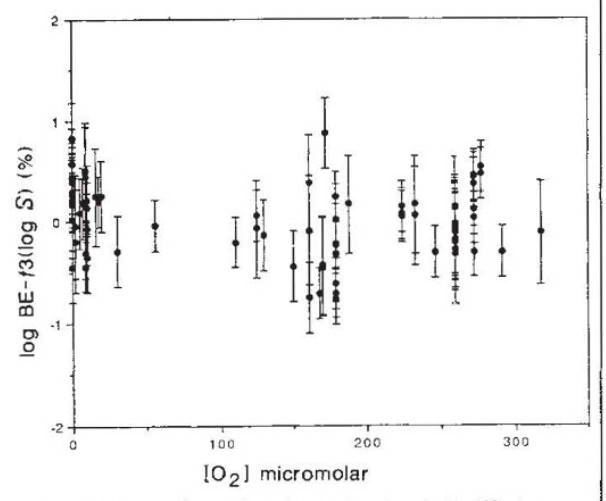

It had been thought that the burial efficiency (BE) of organic carbon in marine sediments is influenced by the concentration of oxygen $\left[\mathrm{O}_{2}\right]$ in ocean bottom waters, so providing a feedback mechanism for controlling atmospheric oxygen levels. But this graph, compiled from 76 separate studies and corrected for differences in sedimentation rates $(f 3(\log S))$, shows it not to be the case.

are set by the presence of fusinite (charcoal) in coals deposited since the Carboniferous (W.G. Chaloner, Royal Holloway and Bedford New College; J.M Robinson, Pennsylvania State University; N.C. Arens, Harvard University). Fusinite is an almost certain indicator of forest fires during the accumulation of plant debris. Its presence sets a lower limit of about 13 per cent on the $\mathrm{O}_{2}$ content of the atmosphere during charcoal formation, since forest fires are unlikely to start and persist at lower $\mathrm{O}_{2}$ concentrations.

The presence of large fossil trees in coals sets a somewhat more poorly defined upper limit on the $\mathrm{O}_{2}$ content of the atmosphere: at $\mathrm{O}_{2}$ concentrations in excess of 30-35 per cent forest fires would probably have been too frequent to allow the growth of large trees, and it is not clear whether the photorespiratory burden imposed by high $\mathrm{O}_{2}$ concentrations is compatible with the record of luxuriant forest growth.

A potentially more precise $\mathrm{O}_{2}$ barometer for the past $100 \mathrm{Myr}$ may be provided by the air bubbles commonly found in amber (G.P. Landis, US Geological Survey; D. Bellis, US Department of State). For this, it needs to be demonstrated that the air in these bubbles was trapped when the amber was formed, and that the compositional changes due to reactions with the surrounding amber can be assessed. The value of this barometer continues to be a matter of fairly heated debate. Landis reported new, but still preliminary data suggesting that the diffusivity of gases in amber is sufficiently low to prevent extensive gas transfer to and from the air bubbles. He proposed that the $\mathrm{O}_{2}$ content of air during the Cretaceous decreased from around 35 to about 22 per cent at the base of the Tertiary (66 Myr ago), and that the percentage of $\mathrm{O}_{2}$ in the atmosphere has remained essentially constant since then.

R. A. Berner (Yale University) described his calculations of the history of atmospheric $\mathrm{O}_{2}$ during the past $570 \mathrm{Myr}$. These are based on estimates of the rates of burial and weathering of organic carbon and pyrite sulphur during the Phanerozoic. The approach is reasonable, since the $\mathrm{O}_{2}$ content of the atmosphere is largely determined by these parameters, but the data base is still somewhat weak. The model suggests that the $\mathrm{O}_{2}$ content of the atmosphere during parts of the Carboniferous and Permian (320-280 Myr ago) was about 35 per cent. The values proposed for the $\mathrm{O}_{2}$ content of the atmosphere during the past $100 \mathrm{Myr}$ disagree with those of Landis.

It is clear that $p_{\mathrm{O}}$, has varied widely during Earth history, but that it has remained within fairly narrow limits during the past $350 \mathrm{Myr}$. This period is about 100 times longer than the residence time of $\mathrm{O}_{2}$ in the atmosphere. The partial pressure of $\mathrm{O}_{2}$ must therefore have been controlled rather tightly during this long period. Specifically, the rate of $\mathrm{O}_{2}$ use during weathering and due to the burning of volcanic gases must have been balanced quite precisely by the rate of $\mathrm{O}_{2}$ production due to the burial of organic carbon and reduced sulphur and iron, largely with marine sediments.

The nature of the control mechanism is still unclear. For some time it looked as if the efficiency with which organic matter is buried with marine sediments is influenced fairly strongly by the $\mathrm{O}_{2}$ concentration of seawater near the seawatersediment interface, and hence somewhat indirectly by the $\mathrm{O}$, content of the atmosphere. But this effect is currently very small, and may not exist at all (see figure). The marine geochemistry of phosphorus now seems to be the best candidate for the source of the long-sought $p_{0}$ control mechanism. We need to know much more about the behaviour of $\mathrm{PO}_{+}^{3-}$ in the oceans to test this idea. Until we do, it is premature to speculate on the reasons for the major changes in $p_{\mathrm{O}}$. during the Earth's history.

Heinrich D. Holland is in the Department of Earth and Planetary Sciences, Harvard University, Cambridge, Massachusetts 02138, USA. 